OPEN ACCESS

Edited by:

Jarrad Scarlett,

University of Washington,

United States

Reviewed by:

Brandon L. Roberts,

University of Massachusetts Amherst,

United States

Kang Ho Kim,

University of Texas Health Science Center at Houston, United States

*Correspondence:

Linda X. Wang

lindwang@chla.usc.edu

Specialty section:

This article was submitted to

Neuroendocrine Science,

a section of the journal

Frontiers in Endocrinology

Received: 21 October 2021

Accepted: 13 December 2021

Published: 18 January 2022

Citation:

Wang LX, Frey MR and Kohli R (2022) The Role of FGF19 and MALRD1 in Enterohepatic Bile Acid Signaling.

Front. Endocrinol. 12:799648.

doi: 10.3389/fendo.2021.799648

\section{The Role of FGF19 and MALRD1 in Enterohepatic Bile Acid Signaling}

\author{
Linda X. Wang ", Mark R. Frey and Rohit Kohli \\ Division of Gastroenterology, Hepatology and Nutrition, Children's Hospital Los Angeles, Keck School of Medicine, \\ University of Southern California, Los Angeles, CA, United States
}

Bile acids are the catabolic end products of cholesterol metabolism that are best known for their role in the digestion of lipids. In the last two decades, extensive investigation has shown bile acids to be important signaling molecules in metabolic processes throughout the body. Bile acids are ligands that can bind to several receptors, including the nuclear receptor farnesoid $X$ receptor $(F X R)$ in ileal enterocytes. FXR activation induces the expression of fibroblast growth factor (FGF) 15/19, a hormone that can modulate bile acid levels, repress gluconeogenesis and lipogenesis, and promote glycogen synthesis. Recent studies have described a novel intestinal protein, MAM and LDL Receptor Class A Domain containing 1 (MALRD1) that positively affects FGF15/19 levels. This signaling pathway presents an exciting target for treating metabolic disease and bile acidrelated disorders.

Keywords: MALRD1, FGF19, bile acid signaling, lipid metabolism, glucose metabolism

\section{INTRODUCTION}

Bile acids are physiological detergent molecules synthesized from cholesterol that were once thought to primarily function in the intestinal tract to solubilize and facilitate absorption of fats, steroids, and fat-soluble vitamins. However, more recent research has revealed their broader role as signaling molecules that activate nuclear receptors and $G$ protein-coupled receptors to modulate a variety of metabolic processes such as glucose homeostasis, lipid metabolism, immune cell function, and cell growth and proliferation (1). Their role in these processes requires a tightly regulated cyclical process of bile acid synthesis in the liver, transport, and reabsorption from the ileum to maintain precise levels in circulation. Any alteration in this homeostasis affects hepatic metabolic processes, potentially resulting in inflammation and development of diseases such as cholestatic liver diseases, dyslipidemia, diabetes, and even cancer $(1,2)$. Numerous studies have demonstrated the importance of the hormone, fibroblast growth factor 19 (FGF19), in the maintenance of this homeostasis. Most recently, a newly identified intestinal protein, MALRD1, has been shown to modulate levels of FGF19 $(3,4)$. This review will provide an overview of bile acid metabolism, enterohepatic bile acid signaling, metabolic effects of FGF19, and MALRD1. 


\section{BILE ACID METABOLISM}

\section{Bile Acid Synthesis}

Bile acids are synthesized from cholesterol through a complex multi-enzyme series of reactions in hepatocytes. The adult human bile acid pool consists of approximately $40 \%$ cholic acid (CA), 40\% chenodeoxycholic acid (CDCA), 20\% secondary bile acid deoxycholic acid (DCA), and trace amounts of lithocholic acid (LCA) (5). There are two main pathways responsible for bile acid synthesis (Figure 1). In the neutral or classic bile acid pathway, the rate-limiting cytochrome P450 enzyme cholesterol $7 \alpha$-hydroxycholesterol (CYP7A1) initiates the conversion of cholesterol to the primary bile acids, CA and CDCA. The intermediate product $7 \alpha$-hydroxy-4cholestene-3-one (C4) is the common precursor for these two bile acids. The microsomal CYP enzyme, sterol $12 \alpha$-hydroxylase (CYP8B1), is required for synthesis of CA.

In the acidic or alternative pathway, cholesterol 27hydroxylase (CYP27A1), a mitochondrial P450 enzyme, catalyzes the first reaction that leads to the final production of CDCA (6). The acidic pathway contributes to less than $10 \%$ of the total bile acid production in humans (7). Of note, the acidic pathway has been found to be more important in those with liver disease and in neonates $(8,9)$.

\section{Bile Acid Conjugation}

The primary bile acids, CA and CDCA, are conjugated with the amino acids glycine and taurine in a 3:1 ratio, depending on the availability of dietary taurine and animal species (e.g., in mice most bile acids are taurine-conjugated) $(10,11)$. Conjugation serves to increase the solubility of the bile acids and enables their transport via bile acid transporters on hepatocytes into the bile canalicular system and subsequently into the gallbladder. It also limits their passive reabsorption as they pass down the biliary system. After a meal, the secretion of cholecystokinin induces gallbladder contraction, which releases its contents into the gastrointestinal tract (5). Greater than $70 \%$ of the stored bile is expelled into the proximal small intestine.

\section{Enterohepatic Circulation}

A minority of secreted bile acids are passively reabsorbed from the proximal small intestine. The majority of bile acids secreted into the intestines each cycle are reabsorbed in the ileum by active transport back into the portal system and circulated back to the liver. Transporters on the apical membrane of ileal enterocytes and on the sinusoidal membrane of the hepatocyte are highly efficient in this process, with recovery of about $95 \%$ of luminal bile acids ( 1 , $11,12)$. The $5 \%$ lost in feces are replenished by de novo hepatic bile acid synthesis (13). This synthesis of bile acids is self-regulated by negative feedback by bile acids returning to the liver (14). This bile acid pool of approximately 4 to $5 \mathrm{~g}$ is recycled 6 to 10 times per day through the coordinated action of several bile acid transporters, the expression of which are controlled at the transcriptional level (Figure 2). The flow of bile also facilitates hepatobiliary secretion of metabolites and xenobiotics (15).

\section{Bile Acid Transformation}

The small percentage of primary bile acids that reach the colon undergo significant structural modifications by intestinal bacteria, leading to the formation of secondary bile acids, deoxycholic acid (DCA) and lithocholic acid (LCA), derived from CA and CDCA respectively. LCA is highly hepatotoxic and is mostly excreted into feces, whereas DCA circulates with the primary bile acids (16).

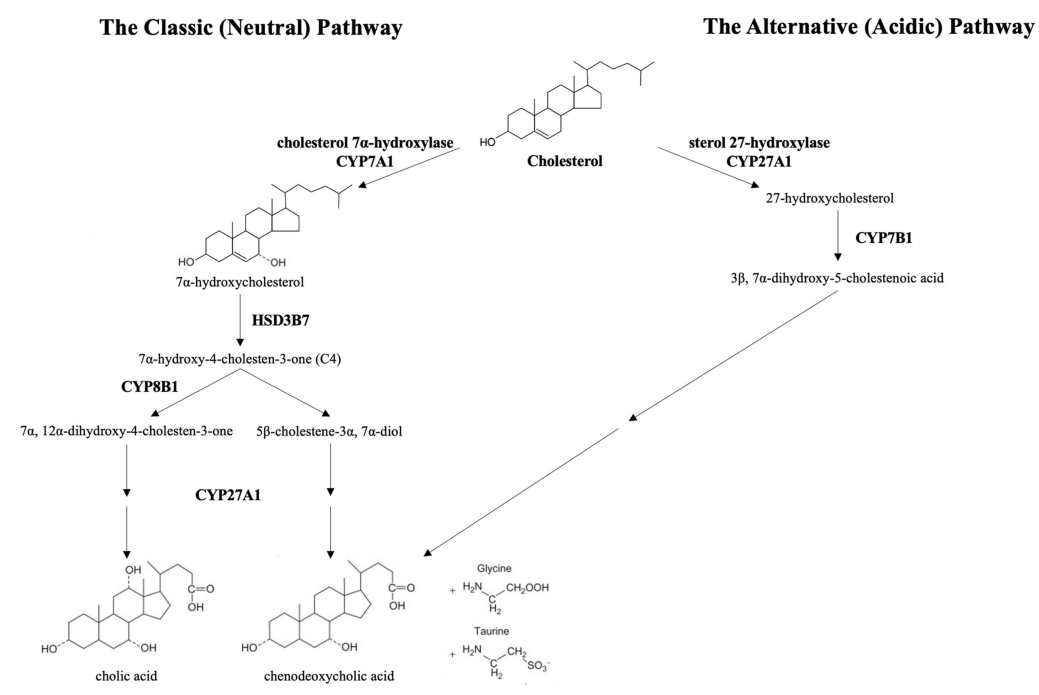

FIGURE 1 | The classic and alternative bile synthetic pathways. CYP7A1, cholesterol $7 \alpha$-hydroxylase, is the rate limiting enzyme in the classic (neutral) pathway. HSD3B7, 3 beta-hydroxysteroid dehydrogenase type 7, creates the common precursor, $7 \alpha$-hydroxy-4-cholesten-3-one (C4), for both primary bile acids. CYP8B1, sterol 12-alpha-hydroxylase, initiates the pathway toward the formation of cholic acid. In the acidic pathway, CYP27A1, sterol 27-hydroxylase, catalyzes the first step toward the formation of chenodeoxycholic acid. The primary bile acids are conjugated to the amino acids, glycine and taurine, prior to excretion into the biliary system. 


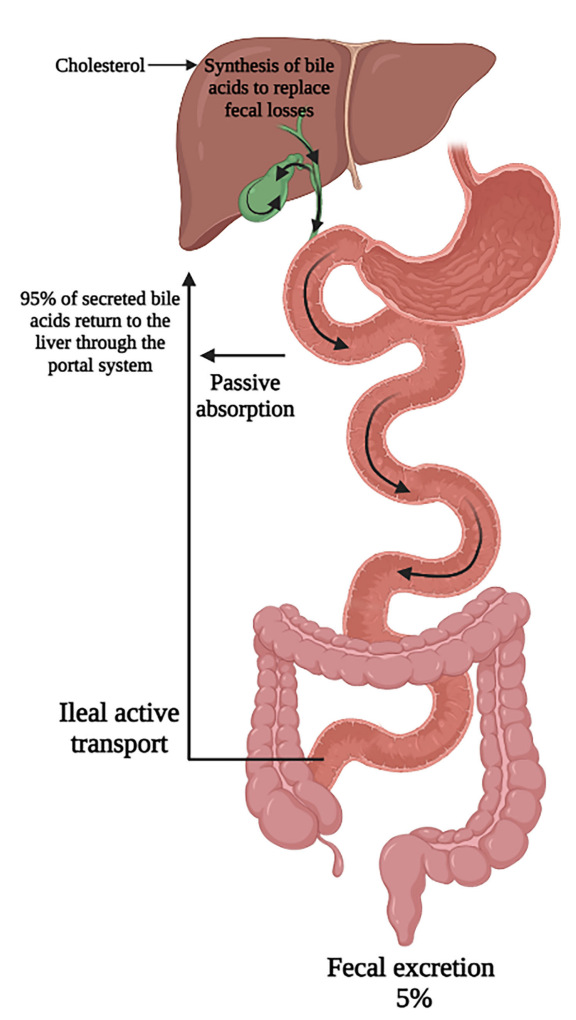

FIGURE 2 | Enterohepatic circulation of bile acids. Secreted bile acids are passively absorbed (minimally) in the proximal intestine and actively transported (majority) in the ileum. This allows for recovery of 95\% of secreted bile acids back to the liver. Figure created on biorender.com.
Bacterial deconjugation creates unconjugated mono- or dihydroxy bile acids, which can be passively absorbed through colonic epithelium and recycled back to the liver. The enzymes that catalyze these transformations are found in bacterial organisms such as Bacteroidetes, Clostridium species, Bifidobacteriaceae, and Enterococcus $(7,16)$. Gut bacteria are thought to benefit from bile metabolism through acquisition of glycine and taurine, which can be used as an energy source in metabolism $(17,18)$. Alterations in intestinal microbiota can therefore have effects on bile acid pool size and composition, relevant to multiple chronic disease states (19-21). The same is true in reverse as changes in intra-luminal bile acid pool can impact the composition of the gut microbiome.

\section{THE ROLE OF BILE ACIDS AS METABOLIC REGULATORS}

Bile acids are now well recognized as ligands for multiple nuclear receptors, including the farnesoid X receptor (FXR), the vitamin $D$ receptor (VDR), the pregnane $X$ receptor (PXR), constitutive androstane receptor (CAR), and the $\mathrm{G}$ protein coupled receptor Takeda G protein receptor 5 (TGR5) (1). Activation of these receptors leads to regulation of genes integral to metabolic processes throughout the body including in the brain, intestine, liver, brown adipose tissue, and macrophages (Table 1). FXR has been implicated in the regulation of enterohepatic circulation, glucose, lipid, and energy metabolism, and tumorigenesis through its downstream effector, FGF 15/19 (mouse and human orthologues).

TABLE 1 | Bile acid receptors and physiological functions.

\begin{tabular}{|c|c|c|c|c|}
\hline Receptor & $\begin{array}{l}\text { Representative } \\
\text { Ligands }\end{array}$ & $\begin{array}{l}\text { Cytogenetic } \\
\text { location }\end{array}$ & Tissue/Cell Expression & Functions \\
\hline $\begin{array}{l}\text { FXR } \\
(\mathrm{NR} 1 \mathrm{H} 4)\end{array}$ & $\begin{array}{l}\text { CDCA }>\text { DCA }>\text { LCA }>C A \\
\text { INT-747, GW4064, } \\
\text { fexaramine, PX-102 }\end{array}$ & $12 q 23.1$ & Liver, intestine, kidney, adrenal gland & $\begin{array}{ll}\text { - } & \text { Bile acid metabolism (22-28) } \\
\text { - } & \text { Glucose metabolism (29) } \\
\text { - } & \text { Lipid metabolism (29) } \\
\text { - } & \text { Liver regeneration (30) } \\
\text { - } & \text { Anti-inflammatory (31) }\end{array}$ \\
\hline VDR (NR111) & $\begin{array}{l}\text { LCA; vitamin D; } \\
\text { LY2108491 }\end{array}$ & $12 \mathrm{q} 13.11$ & $\begin{array}{l}\text { Liver, intestine, gallbladder, bone, kidney, parathyroid, skin, bone } \\
\text { marrow }\end{array}$ & $\begin{array}{ll}\text { - } & \text { Bile acid synthesis (32) } \\
\text { - } & \text { Xenobiotic detoxification (33) } \\
\text { - } & \text { Calcium homeostasis (34) } \\
\text { - } & \text { Antimicrobial defense (35) }\end{array}$ \\
\hline $\mathrm{PXR}(\mathrm{NR} 1 \mathrm{I} 2)$ & $\begin{array}{l}\text { LCA, DCA, CA; } \\
\text { progesterone; rifampicin }\end{array}$ & $3 q 13.33$ & Liver, intestine, immune cells & $\begin{array}{ll}\text { - } & \text { Bile acid synthesis }(36) \\
\text { - } & \text { Glucose metabolism }(37) \\
\text { - } & \text { Lipid metabolism }(37,38) \\
\text { - } & \text { Drug metabolism }(37) \\
\text { - } & \text { Anti-inflammatory }(37,39)\end{array}$ \\
\hline CAR (NR1I3) & $\begin{array}{l}\text { CA, 6-keto-LCA, } \\
\text { 12-keto } \\
\text { LCA; phenobarbital }\end{array}$ & $1 q 23.3$ & Liver, intestine, kidney & $\begin{array}{ll}\text { - } & \text { Xenobiotic detoxification } \\
& (40,41) \\
\text { - } \quad \text { Glucose metabolism }(42,43) \\
\text { - } \quad \text { Lipid metabolism (43) }\end{array}$ \\
\hline TGR5 & $\begin{array}{l}\text { LCA }>\text { DCA }>\text { CDCA }>C A \\
\text { INT-767; oleanolic acid }\end{array}$ & $2 q 35$ & Liver, intestine, gallbladder, muscle, brown adipose, brain & $\begin{array}{ll}\text { - } & \text { Glucose homeostasis (44) } \\
\text { - } & \text { Intestinal motility (45) } \\
\text { - } & \text { Enellbladder relaxation (46) } \\
\text { - } & \text { Anti-inflammatory (48) }\end{array}$ \\
\hline
\end{tabular}




\section{Regulation of Enterohepatic Circulation}

The enterohepatic circulation of bile acids serves to control bile acid synthesis through a negative feedback mechanism by activation of FXR in the intestine and liver. In the ileum, bile acids are transported across the apical membrane via the apical sodium dependent bile acid transporter (ASBT). They bind to FXR and induce expression of the gene encoding FGF 15/19. FGF $15 / 19$ is then secreted through the circulation to the liver where it binds to the FGF receptor (FGFR) 4 and its co-receptor, $\beta$-Klotho, on the hepatocyte cell membrane. Through subsequent activation of both extracellular signal-regulated kinase (ERK) and Jun N-terminal kinase (JNK) pathways, CYP7A1 transcription is downregulated. In the liver, activation of FXR induces expression of SHP (encodes short heterodimeric partner, SHP) which inhibits CYP8B1 transcription and to a lesser degree CYP7A1 (22) (Figure 3). Rats fed with bile acids showed strongly reduced activity of CYP7A1 and bile acid synthesis, whereas interruption of the enterohepatic circulation with use of bile acid binding resins (e.g. cholestyramine) increased the activity of CYP7A1 (49). A study in mice deficient in ileal apical sodium-dependent bile acid transporter (ASBT, SLC10A2) showed reduced intestine Fgf15 expression, higher hepatic $C y p 7 A 1$ expression and resistance to atherosclerosis development (50). Additionally, mice lacking the intestinal basolateral bile acid transporter, organic solute transporter $\alpha$ and $\beta$ (OST $\alpha$-OST $\beta$, SLC51A-SLC51B), exhibited reduced bile acid pool size with a decrease in hepatic bile acid synthesis resulting from intracellular bile acid retention and increased Fgf15 expression (51).

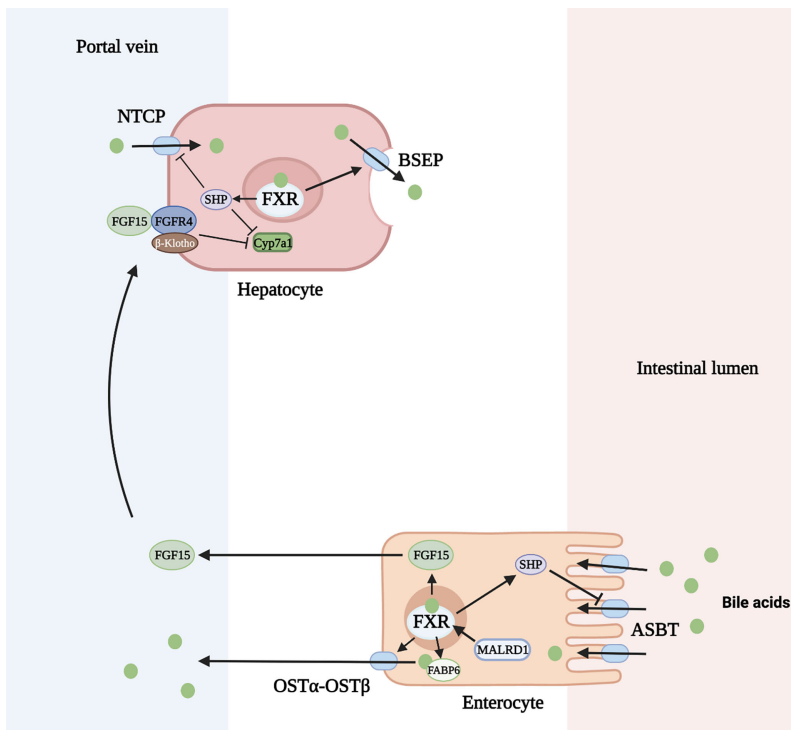

FIGURE 3 | Regulation of bile acid homeostasis by FXR (farnesoid X receptor) and FGF15 (fibroblast growth factor 15). ASBT, apical sodium dependent bile acid transporter; BSEP, bile salt export pump; FGFR4, FGF receptor 4; FABP6, fatty acid binding protein 6; NTCP, Na+-taurocholate cotransporting polypeptide; OST $\alpha$-OST $\beta$, organic solute transporter $\alpha$ and $\beta$; SHP, short heterodimeric partner. Figure created on biorender.com.
In addition to inhibition of bile acid synthesis, FXR activation also regulates bile acid transport. FXR inhibits hepatic bile acid uptake and ileal bile acid uptake through decreased production of the sodium-dependent transporter, $\mathrm{Na}^{+}$-taurocholate cotransporting polypeptide (NTCP, SLC10A1), and ASBT, respectively. This is mediated through induction of SHP which inhibits the retinoic acid and retinoid $\mathrm{X}$ receptor (RAR/RXR) heterodimer on the gene promoter $(23,24) . \mathrm{FXR}^{+/+}$mice fed a $1 \%$ cholic acid diet show a marked reduction of NTCP RNA levels. $\mathrm{FXR}^{-1-}$ mice fed the same diet show no change in NTCP or bile acid import (25). In contrast, FXR activation upregulates the bile salt export pump (BSEP, $A B C B 11$ ) on the apical membrane of hepatocytes and OST $\alpha$-OST $\beta$ transporter on the apical membrane of enterocytes. FXR forms a heterodimer with retinoid $\mathrm{X}$ receptor (RXR) which binds to an inverted repeat (IR)-1 element on the gene promoter for BSEP or OST $\alpha$-OST $\beta$ to induce the transporter production in a positive feed forward manner (26). This mechanism has been demonstrated by the induction of $A B C B 11 \mathrm{mRNA}$ and protein in mice fed a large dose of bile acid. FXR-deficient mice have low levels of BSEP that do not change after being fed a bile-acid enriched diet (25). Similarly, elevated SLC51A-SLC51B mRNA levels were seen after wild-type mice were administered a synthetic FXR agonist, but this response was decreased in FXR-null mice (27). Lastly, the production of cytosolic intestinal bile acid binding protein (fatty acid binding protein 6, FABP6) is upregulated by bile acids through activation of nuclear FXR allowing increased transport of bile acids through the enterocyte (28).

It is evident that FXR and FGF $15 / 19$ have essential roles in the enterohepatic circulation of bile acids. Dysregulation of FXR target genes not only impairs enterohepatic circulation, but also results in cholestatic disease.

\section{Glucose Metabolism}

Many studies have implicated the FXR-FGF19 signaling axis in regulation of hepatic glucose metabolism. FGF15/19 acts as a post-prandial hormone that enhances glycogen synthesis and inhibits gluconeogenesis independent of insulin. In humans, serum FGF19 concentrations peak 2 to 3 hours following a meal, with a half-life of 30 minutes $(52,53)$. Glycogen synthesis is mediated through activation of ERK pathway with increased phosphorylation of glycogen synthase kinase (GSK) $3 \alpha$ and GSK3 $\beta$ leading to decreased inhibition of glycogen synthase. FGF15 deficient mice have impaired glucose uptake and decreased hepatic glycogen compared to wild-type mice. Administration of FGF19 reverses these effects. Inhibition of gluconeogenesis occurs through inactivation of cMAP response element-binding protein (CREB) (Figure 4). Both processes were shown to occur independently of insulin (54). However, insulin does increase hepatic FGFR4, indicating a priming of FGF19 action (55).

Previous research has shown that FGF19 administered to cerebral ventricles results in decreased food intake, lower glucose levels and improved insulin sensitivity in mice fed a high fat diet $(56,57)$ indicating a potential link between diabetes and FGF19. However, the data in humans has been inconsistent (58-60). The 


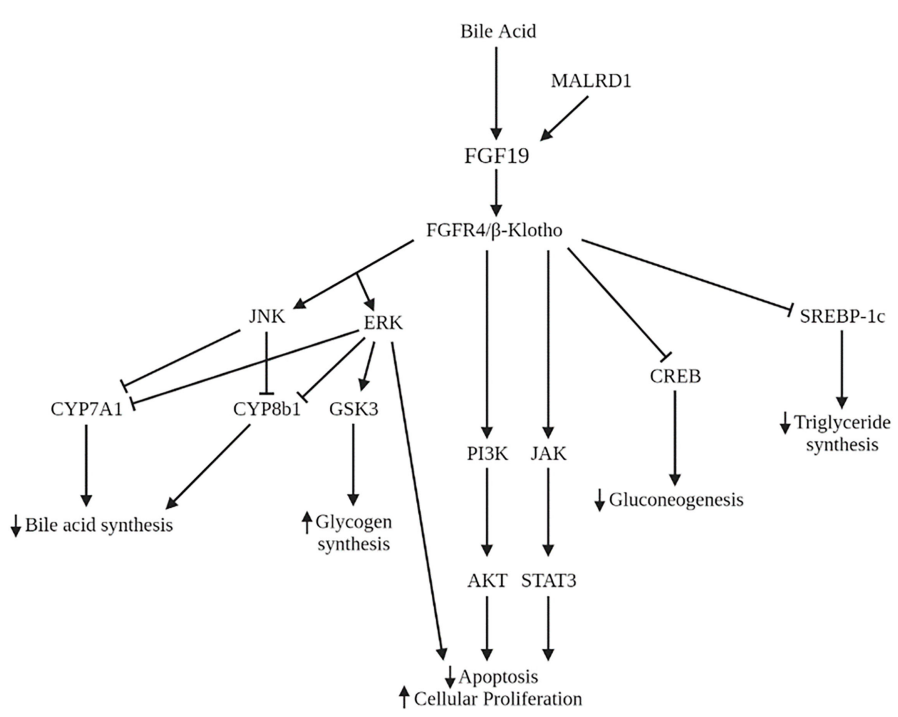

FIGURE 4 | Signaling pathways of FGF19 and MALRD1. AKT, serine/threonine protein kinase B; CREB, cMAP response element-binding protein; ERK, extracellular signal-regulated kinase; GSK3, glycogen synthase kinase; JAK, Janus kinase; JNK, Jun N-terminal kinase; PI3K, phosphoinositide 3-kinase; STAT3, signal transducer and activator of transcription 3; SREBP-1c, sterol regulatory element binding protein-1C.

most suggestive evidence was noted in diabetic patients who have remission of diabetes after Roux-en-Y gastric bypass surgery. Pre-operatively, those with diabetes had lower FGF19 and bile acid levels than nondiabetic patients. Post-operatively, levels of FGF19 and bile acids rose higher in diabetic patients than nondiabetic patients (61).

\section{Lipid Metabolism}

In addition to its role in carbohydrate storage, FGF19 also has longterm effects on hepatic lipid metabolism. FGF19 inhibits the synthesis of the transcription factor sterol regulatory element binding protein-1c (SREBP-1c), which activates the transcription of genes necessary for fatty acid synthesis. In addition, FGF19 increases expression of SHP which also acts to inhibit lipogenic enzyme synthesis (62) (Figure 4). Administration of FGF19 to FXR-null mice prevented hepatic fat deposition and decreased liver enzyme levels (63). Clinically, pediatric patients with non-alcoholic fatty liver disease (NAFLD) have demonstrated decreased FGF19 levels $(64,65)$. FGF19 levels were shown to be inversely associated with development of steatohepatitis and fibrosis (64). Lastly, adults with NAFLD and insulin resistance show an impaired response to FGF19 compared to those with NAFLD and without insulin resistance (66). This impairment may further contribute to the dysregulation of lipid homeostasis in NAFLD.

Given the findings of these studies, there are emerging medical therapies for treatment of nonalcoholic steatohepatitis (NASH) that include agonists of FXR and FGF19 analogs. Of those in clinical trials, obeticholic acid (OCA), a FXR agonist, has been shown to improve fibrosis and prevent progression of fibrotic disease (67). An engineered FGF19 analog, NGM282, produced a significant reduction in liver fat content $(>30 \%)$ in patients with NASH. Liver fat content normalized in up to $39 \%$ of patients (68).

\section{Energy Metabolism}

By regulating both glucose and lipid metabolism, FGF19 plays a central role in energy balance. Several studies have observed that plasma FGF19 levels are significantly lower in obese patients compared to nonobese controls (69-71). A study of transgenic mice overexpressing FGF19 demonstrated increased energy expenditure with reduction in fat mass (72). When fed a highfat diet, the transgenic mice did not become obese or diabetic. This is thought to be due to higher oxygen consumption, increased insulin sensitivity, and increase in brown adipose tissue activity. The same group later reported that administration of FGF19 to obese mice resulted in increased metabolic rate, decreased respiratory quotient, and prevention or reversal of diabetes (73).

These metabolic observations suggest that FGF19 may be a potential candidate for treatment of obesity. Modified forms of FGF19 have been created that have been effective in reducing body weight, plasma glucose and triglyceride levels in diet induced obesity (74). These variants were successful in uncoupling the metabolic effects of FGF19 from its effects on hepatocyte proliferation.

\section{Hepatocyte Growth and Proliferation}

The FGF15/19-FGFR4 signaling pathway has been implicated in the initiation and progression of several cancers including lung, breast, colorectal, and hepatocellular carcinoma (HCC). The initial evidence of FGF19's role in hepatocyte growth came from observations in FGF19 transgenic mice who developed hepatocellular carcinomas by 12 months of age. Administration of FGF19 led to increases in hepatocellular proliferation which preceded tumor development (75). Tumor formation in these mice was subsequently prevented by monoclonal antibodies that selectively blocked the interaction of FGF19 with FGFR4 (76) or by deficiency in FGFR4 (77). In humans, FGF19 and FGFR4 are 
both overexpressed in HCC compared to noncancerous liver tissue (76). FGF19 is an independent negative prognostic factor for survival (78). The mechanism underlying this process is the dysregulation of RAS-RAF-ERK1/12MAPK, PI3K-AKT, and STAT3 pathways leading to decreased apoptosis and increased cell growth and proliferation (79-81) (Figure 4). Furthermore, FGF19 facilitates resistance to apoptosis (82) and promotes metastasis (83) through GSK3 $\beta$ activation. Therapies aimed at inhibiting FGF19 and FGFR4 are in various phases of development, including clinical trials for several malignancies including HCC (84). Side effects of these therapies often include increased bile acid synthesis, change in bile acid transporter expression, and enhanced enterohepatic circulation.

\section{MALRD1, A REGULATOR OF BILE ACID SIGNALING}

The many roles of FGF15/19, as detailed above, in metabolism has spurred interest in potential regulators of its activity. In the last decade, one intestinal protein, MALRD1, has been identified that influences the production of FGF15/19 in enterocytes.

The locus was initially identified after an observation that a mouse sub-strain, C57BL/6ByJ (B6By), was resistant to dietinduced hypercholesterolemia and atherosclerosis seen in another closely related common strain, C57BL/6J (B6J) (85). There were however no differences noted in food consumption and cholesterol absorption. The B6By mice showed increased bile acid excretion and an enlarged bile acid pool with elevated expression of several genes involved in bile acid synthesis and transport, including Cyp7a1 (86). It was established that serum bile acid levels co-segregate with cholesterol levels, indicating that the same locus was responsible for both phenotypes. Through genetic mapping and sequencing, the gene was identified on mouse chromosome 2 and named Diet 1.

Diet 1 encodes a $236 \mathrm{kDa}$ protein that contains nine copies of the MAM (meprin-A5-tyrosine phosphatase $\mu$ ) domain which are interspersed with nine copies of the low-density lipoprotein receptor (LDLR) class A domain. The official gene name was since been changed to MAM and LDL Receptor Class A Domain containing 1 (MALRD1 human, Malrd1 mice). The amino acid sequence of MALRD1 is highly conserved between mouse and human at $70 \%$ identity, as well as other species including zebrafish, chicken, frog, and rat. MALRD1 is expressed mainly in the small intestine and in lower levels at the kidney cortex. Within the intestine, MALRD1 expression was localized to the epithelial cell layer (87).

\section{The Effects of MALRD1 on FGF 15/19}

In the seminal paper on MALRD1, deficiency of this protein was shown to reduce ileal Fgf15 mRNA and protein levels. B6By mice with rescued Malrd1 expression had increased Fgf15 mRNA and protein secretion by approximately 3 -fold and reduced $C y p 7 a 1$ mRNA levels (87). A similar effect in FGF15 protein secretion was seen with overexpression and knockdown of Malrd1 in cultured intestinal cells. In contrast, Fgf15 mRNA levels were minimally affected by either overexpression or knockdown of Malrd1. MALRD1 was shown to interact and co-localize with
FGF19 within an intracellular compartment (87). Taken together, these data suggest that MALRD1 influences FGF15/ 19 levels at both the mRNA and post-transcriptional levels.

\section{Association With Disease}

A recent study of Malrd1 deficient mice found that these mice not only had elevated bile acids and reduced FGF15 levels, but also reduced gastrointestinal transit and increased intestinal luminal water content (88). This is similar to the phenotype seen in patients with bile acid diarrhea (BAD), in which increased luminal bile acid levels induce water secretion and accelerate colonic transit. Thus far, there has been no reported association of MALRD1 with clinical disease though many $M A L R D 1$ variants have been found. One variant is noted to be more common in individuals with $\mathrm{BAD}$ and is associated with decreased levels of FGF19 secretion $(3,88)$.

A genetic analysis of patients with hepatocellular carcinoma found MALRD1 (DIET1) to be a co-expressing protein coding gene (PCG) for a long non-coding RNA sequence associated with hepatocellular carcinoma. Although the study did not show any diagnostic or prognostic value to MALRD1 expression, it is interesting to note this association due to the role of FGF19 in hepatocellular growth and proliferation (89). Further studies will need to be undertaken to elucidate the relationship between MALRD1 and the pathogenesis of this disease.

The extensive role of FGF19 in metabolic processes of lipid metabolism and glucose metabolism provides an intriguing potential of MALRD1 in the regulation of these processes as well. Studies are currently in place to explore the influence of MALRD1 in progression to NAFLD. The absence of MALRD1 can be theorized to result in increased hepatic steatosis and fibrosis due to its effects on the reduction of FGF19 levels.

A recent study examining the genetic risk factors for development of diabetic retinopathy revealed a single nucleotide polymorphism (SNP), rs12267418, located within the MALRD1 gene to be associated with severe disease in Caucasians (90). Another study in a Chinese diabetic population also found 2 SNPs within the MALRD1 gene, although an association was not found. This intriguing finding raises the question of whether ethnic differences or epigenetic effects may be responsible for the differing results (91).

Additionally, the role of MALRD1 in intestinal cellular proliferation and growth is being examined. Previously, administration of CDCA has been shown to induce FGF19, GLP-1, and GLP-2 levels along with increased intestinal mucosal growth via the FXR and TGR5 pathways. Further studies are being undertaken to elucidate the potential effects of MALRD1 on the TGR5 pathway.

\section{CONCLUSION}

Research in the last few decades has revealed an important role for bile acids in the regulation of metabolic processes in the body. Maintenance of bile acid homeostasis is critical for prevention of metabolic disorders ranging from cholestasis to diabetes. The identification of components of bile acid signaling pathways has led to a deeper understanding of the regulatory mechanisms 
involved and provides a molecular basis for developing therapies for treatment of metabolic diseases. The newly discovered intestinal protein, MALRD1, offers another potential target for future research.

\section{AUTHOR CONTRIBUTIONS}

All authors contributed to the conception of the review framework. LW wrote and edited the manuscript. RK and MF

\section{REFERENCES}

1. Chiang JYL, Ferrell JM. Bile Acid Metabolism in Liver Pathobiology. Gene Expr (2018) 18(2):71-87. doi: 10.3727/105221618X15156018385515

2. Copple BL, Li T. Pharmacology of Bile Acid Receptors: Evolution of Bile Acids From Simple Detergents to Complex Signaling Molecules. Pharmacol Res (2016) 104:9-21. doi: 10.1016/j.phrs.2015.12.007

3. Reue K, Lee JM, Vergnes L. Diet1 is a Regulator of Fibroblast Growth Factor 15/19-Dependent Bile Acid Synthesis. Dig Dis (2015) 33(3):307-13. doi: $10.1159 / 000371649$

4. Li T, Chiang JY. Bile Acids as Metabolic Regulators. Curr Opin Gastroenterol (2015) 31(2):159-65. doi: 10.1097/MOG.0000000000000156

5. Li T, Apte U. Bile Acid Metabolism and Signaling in Cholestasis, Inflammation, and Cancer. Adv Pharmacol (2015) 74:263-302. doi: 10.1016/bs.apha.2015.04.003

6. Swell L, Gustafsson J, Schwartz CC, Halloran LG, Danielsson H, Vlahcevic ZR. An In Vivo Evaluation of the Quantitative Significance of Several Potential Pathways to Cholic and Chenodeoxycholic Acids From Cholesterol in Man. J Lipid Res (1980) 21(4):455-66. doi: 10.1016/S0022-2275(20)39796-0

7. Ridlon JM, Kang DJ, Hylemon PB, Bajaj JS. Bile Acids and the Gut Microbiome. Curr Opin Gastroenterol (2014) 30(3):332-8. doi: 10.1097/ MOG.0000000000000057

8. Vlahcevic ZR, Schwartz CC, Gustafsson J, Halloran LG, Danielsson H, Swell L. Biosynthesis of Bile Acids in Man. Multiple Pathways to Cholic Acid and Chenodeoxycholic Acid. J Biol Chem (1980) 255(7):2925-33. doi: 10.1016/ S0021-9258(19)85829-5

9. McCormick WC3rd, Bell CC Jr, Swell L, Vlahcevic ZR. Cholic Acid Synthesis as an Index of the Severity of Liver Disease in Man. Gut (1973) 14(11):895902. doi: 10.1136/gut.14.11.895

10. Haslewood GA. Bile Salt Evolution. J Lipid Res (1967) 8(6):535-50. doi: 10.1016/S0022-2275(20)38873-8

11. Dawson PA, Karpen SJ. Intestinal Transport and Metabolism of Bile Acids. J Lipid Res (2015) 56(6):1085-99. doi: 10.1194/jlr.R054114

12. Chiang JY. Bile Acids: Regulation of Synthesis. J Lipid Res (2009) 50(10):195566. doi: 10.1194/jlr.R900010-JLR200

13. Kullak-Ublick GA, Stieger B, Meier PJ. Enterohepatic Bile Salt Transporters in Normal Physiology and Liver Disease. Gastroenterology (2004) 126(1):322-42. doi: 10.1053/j.gastro.2003.06.005

14. Chiang JY. Bile Acid Metabolism and Signaling. Compr Physiol (2013) 3 (3):1191-212. doi: 10.1002/cphy.c120023

15. Boyer JL. Bile Formation and Secretion. Compr Physiol (2013) 3(3):1035-78. doi: $10.1002 /$ cphy.c120027

16. Ridlon JM, Kang DJ, Hylemon PB. Bile Salt Biotransformations by Human Intestinal Bacteria. J Lipid Res (2006) 47(2):241-59. doi: 10.1194/jlr.R500013JLR200

17. Wang W, Wu Z, Dai Z, Yang Y, Wang J, Wu G. Glycine Metabolism in Animals and Humans: Implications for Nutrition and Health. Amino Acids (2013) 45(3):463-77. doi: 10.1007/s00726-013-1493-1

18. Long SL, Gahan CGM, Joyce SA. Interactions Between Gut Bacteria and Bile in Health and Disease. Mol Aspects Med (2017) 56:54-65. doi: 10.1016/ j.mam.2017.06.002

19. Staley C, Weingarden AR, Khoruts A, Sadowsky MJ. Interaction of Gut Microbiota With Bile Acid Metabolism and Its Influence on Disease States. Appl Microbiol Biotechnol (2017) 101(1):47-64. doi: 10.1007/s00253-016-8006-6 provided guidance and edited the manuscript. All authors contributed to the article and approved the submitted version.

\section{FUNDING}

This work was supported by North American Society for Pediatric Gastroenterology, Hepatology \& Nutrition (NASPGHAN) Foundation/Nestlé Nutrition Research Young Investigator Development Grant.

20. Sayin SI, Wahlstrom A, Felin J, Jantti S, Marschall HU, Bamberg K, et al. Gut Microbiota Regulates Bile Acid Metabolism by Reducing the Levels of TauroBeta-Muricholic Acid, a Naturally Occurring FXR Antagonist. Cell Metab (2013) 17(2):225-35. doi: 10.1016/j.cmet.2013.01.003

21. Duboc H, Rajca S, Rainteau D, Benarous D, Maubert MA, Quervain E, et al. Connecting Dysbiosis, Bile-Acid Dysmetabolism and Gut Inflammation in Inflammatory Bowel Diseases. Gut (2013) 62(4):531-9. doi: 10.1136/gutjnl2012-302578

22. Kong B, Wang L, Chiang JY, Zhang Y, Klaassen CD, Guo GL. Mechanism of Tissue-Specific Farnesoid X Receptor in Suppressing the Expression of Genes in Bile-Acid Synthesis in Mice. Hepatology (2012) 56(3):1034-43. doi: 10.1002/hep. 25740

23. Denson LA, Sturm E, Echevarria W, Zimmerman TL, Makishima M, Mangelsdorf DJ, et al. The Orphan Nuclear Receptor, Shp, Mediates Bile Acid-Induced Inhibition of the Rat Bile Acid Transporter, Ntcp. Gastroenterology (2001) 121(1):140-7. doi: 10.1053/gast.2001.25503

24. Neimark E, Chen F, Li X, Shneider BL. Bile Acid-Induced Negative Feedback Regulation of the Human Ileal Bile Acid Transporter. Hepatology (2004) 40 (1):149-56. doi: 10.1002/hep.20295

25. Sinal CJ, Tohkin M, Miyata M, Ward JM, Lambert G, Gonzalez FJ. Targeted Disruption of the Nuclear Receptor FXR/BAR Impairs Bile Acid and Lipid Homeostasis. Cell (2000) 102(6):731-44. doi: 10.1016/S0092-8674(00)00062-3

26. Ananthanarayanan M, Balasubramanian N, Makishima M, Mangelsdorf DJ, Suchy FJ. Human Bile Salt Export Pump Promoter Is Transactivated by the Farnesoid X Receptor/Bile Acid Receptor. J Biol Chem (2001) 276(31):2885765. doi: 10.1074/jbc.M011610200

27. Frankenberg T, Rao A, Chen F, Haywood J, Shneider BL, Dawson PA Regulation of the Mouse Organic Solute Transporter Alpha-Beta, OstalphaOstbeta, by Bile Acids. Am J Physiol Gastrointest Liver Physiol (2006) 290(5): G912-22. doi: 10.1152/ajpgi.00479.2005

28. Dawson PA. Role of the Intestinal Bile Acid Transporters in Bile Acid and Drug Disposition. Handb Exp Pharmacol (2011) 201):169-203. doi: 10.1007/ 978-3-642-14541-4_4

29. Claudel T, Staels B, Kuipers F. The Farnesoid X Receptor: A Molecular Link Between Bile Acid and Lipid and Glucose Metabolism. Arterioscler Thromb Vasc Biol (2005) 25(10):2020-30. doi: 10.1161/01.ATV.0000178994.21828.a7

30. Chen WD, Wang YD, Zhang L, Shiah S, Wang M, Yang F, et al. Farnesoid X Receptor Alleviates Age-Related Proliferation Defects in Regenerating Mouse Livers by Activating Forkhead Box M1b Transcription. Hepatology (2010) 51 (3):953-62. doi: 10.1002/hep.23390

31. Hollman DA, Milona A, van Erpecum KJ, van Mil SW. Anti-Inflammatory and Metabolic Actions of FXR: Insights Into Molecular Mechanisms. Biochim Biophys Acta (2012) 1821(11):1443-52. doi: 10.1016/j.bbalip.2012.07.004

32. Han S, Chiang JY. Mechanism of Vitamin D Receptor Inhibition of Cholesterol 7alpha-Hydroxylase Gene Transcription in Human Hepatocytes. Drug Metab Dispos (2009) 37(3):469-78. doi: 10.1124/dmd. 108.025155

33. Makishima M, Lu TT, Xie W, Whitfield GK, Domoto H, Evans RM, et al. Vitamin D Receptor as an Intestinal Bile Acid Sensor. Science (2002) 296 (5571):1313-6. doi: 10.1126/science.1070477

34. Norman AW. Minireview: Vitamin D Receptor: New Assignments for an Already Busy Receptor. Endocrinology (2006) 147(12):5542-8. doi: 10.1210/ en.2006-0946 
35. D'Aldebert E, Biyeyeme Bi Mve MJ, Mergey M, Wendum D, Firrincieli D, Coilly A, et al. Bile Salts Control the Antimicrobial Peptide Cathelicidin Through Nuclear Receptors in the Human Biliary Epithelium. Gastroenterology (2009) 136(4):1435-43. doi: 10.1053/j.gastro.2008.12.040

36. Li T, Chiang JY. Mechanism of Rifampicin and Pregnane X Receptor Inhibition of Human Cholesterol 7 Alpha-Hydroxylase Gene Transcription. Am J Physiol Gastrointest Liver Physiol (2005) 288(1):G74-84. doi: 10.1152/ ajpgi.00258.2004

37. Ihunnah CA, Jiang M, Xie W. Nuclear Receptor PXR, Transcriptional Circuits and Metabolic Relevance. Biochim Biophys Acta (2011) 1812(8):956-63. doi: 10.1016/j.bbadis.2011.01.014

38. Zhou J, Febbraio M, Wada T, Zhai Y, Kuruba R, He J, et al. Hepatic Fatty Acid Transporter Cd36 Is a Common Target of LXR, PXR, and Ppargamma in Promoting Steatosis. Gastroenterology (2008) 134(2):556-67. doi: 10.1053/ j.gastro.2007.11.037

39. Wallace K, Cowie DE, Konstantinou DK, Hill SJ, Tjelle TE, Axon A, et al. The PXR Is a Drug Target for Chronic Inflammatory Liver Disease. J Steroid Biochem Mol Biol (2010) 120(2-3):137-48. doi: 10.1016/j.jsbmb.2010.04.012

40. Uppal H, Toma D, Saini SP, Ren S, Jones TJ, Xie W. Combined Loss of Orphan Receptors PXR and CAR Heightens Sensitivity to Toxic Bile Acids in Mice. Hepatology (2005) 41(1):168-76. doi: 10.1002/hep.20512

41. Saini SP, Sonoda J, Xu L, Toma D, Uppal H, Mu Y, et al. A Novel Constitutive Androstane Receptor-Mediated and CYP3A-Independent Pathway of Bile Acid Detoxification. Mol Pharmacol (2004) 65(2):292-300. doi: 10.1124/ mol.65.2.292

42. Miao J, Fang S, Bae Y, Kemper JK. Functional Inhibitory Cross-Talk Between Constitutive Androstane Receptor and Hepatic Nuclear Factor-4 in Hepatic Lipid/Glucose Metabolism is Mediated by Competition for Binding to the DR1 Motif and to the Common Coactivators, GRIP-1 and PGC-1alpha. J Biol Chem (2006) 281(21):14537-46. doi: 10.1074/jbc.M510713200

43. Gao J, Xie W. Targeting Xenobiotic Receptors PXR and CAR for Metabolic Diseases. Trends Pharmacol Sci (2012) 33(10):552-8. doi: 10.1016/ j.tips.2012.07.003

44. Katsuma S, Hirasawa A, Tsujimoto G. Bile Acids Promote Glucagon-Like Peptide-1 Secretion Through TGR5 in a Murine Enteroendocrine Cell Line STC-1. Biochem Biophys Res Commun (2005) 329(1):386-90. doi: 10.1016/ j.bbrc.2005.01.139

45. Alemi F, Poole DP, Chiu J, Schoonjans K, Cattaruzza F, Grider JR, et al. The Receptor TGR5 Mediates the Prokinetic Actions of Intestinal Bile Acids and Is Required for Normal Defecation in Mice. Gastroenterology (2013) 144 (1):145-54. doi: 10.1053/j.gastro.2012.09.055

46. Li T, Holmstrom SR, Kir S, Umetani M, Schmidt DR, Kliewer SA, et al. The G Protein-Coupled Bile Acid Receptor, TGR5, Stimulates Gallbladder Filling. Mol Endocrinol (2011) 25(6):1066-71. doi: 10.1210/me.2010-0460

47. Watanabe M, Houten SM, Mataki C, Christoffolete MA, Kim BW, Sato H, et al. Bile Acids Induce Energy Expenditure by Promoting Intracellular Thyroid Hormone Activation. Nature (2006) 439(7075):484-9. doi: 10.1038/nature04330

48. Pols TW, Noriega LG, Nomura M, Auwerx J, Schoonjans K. The Bile Acid Membrane Receptor TGR5 as an Emerging Target in Metabolism and Inflammation. J Hepatol (2011) 54(6):1263-72. doi: 10.1016/j.jhep.2010. 12.004

49. Pandak WM, Vlahcevic ZR, Heuman DM, Redford KS, Chiang JY, Hylemon PB. Effects of Different Bile Salts on Steady-State Mrna Levels and Transcriptional Activity of Cholesterol 7 Alpha-Hydroxylase. Hepatology (1994) 19(4):941-7. doi: 10.1002/hep.1840190421

50. Lan T, Haywood J, Dawson PA. Inhibition of Ileal Apical But Not Basolateral Bile Acid Transport Reduces Atherosclerosis in Apoe(-)/(-) Mice. Atherosclerosis (2013) 229(2):374-80. doi: 10.1016/j.atherosclerosis.2013.05.017

51. Rao A, Haywood J, Craddock AL, Belinsky MG, Kruh GD, Dawson PA. The Organic Solute Transporter Alpha-Beta, Ostalpha-Ostbeta, Is Essential for Intestinal Bile Acid Transport and Homeostasis. Proc Natl Acad Sci USA (2008) 105(10):3891-6. doi: 10.1073/pnas.0712328105

52. Potthoff MJ, Kliewer SA, Mangelsdorf DJ. Endocrine Fibroblast Growth Factors 15/19 and 21: From Feast to Famine. Genes Dev (2012) 26(4):31224. doi: $10.1101 /$ gad.184788.111

53. Lundasen T, Galman C, Angelin B, Rudling M. Circulating Intestinal Fibroblast Growth Factor 19 has a Pronounced Diurnal Variation and
Modulates Hepatic Bile Acid Synthesis in Man. J Intern Med (2006) 260 (6):530-6. doi: 10.1111/j.1365-2796.2006.01731.x

54. Kir S, Beddow SA, Samuel VT, Miller P, Previs SF, Suino-Powell K, et al. FGF19 as a Postprandial, Insulin-Independent Activator of Hepatic Protein and Glycogen Synthesis. Science (2011) 331(6024):1621-4. doi: 10.1126/ science. 1198363

55. Shin DJ, Osborne TF. FGF15/FGFR4 Integrates Growth Factor Signaling With Hepatic Bile Acid Metabolism and Insulin Action. J Biol Chem (2009) 284(17):11110-20. doi: 10.1074/jbc.M808747200

56. Morton GJ, Matsen ME, Bracy DP, Meek TH, Nguyen HT, Stefanovski D, et al. FGF19 Action in the Brain Induces Insulin-Independent Glucose Lowering. J Clin Invest (2013) 123(11):4799-808. doi: 10.1172/JCI70710

57. Ryan KK, Kohli R, Gutierrez-Aguilar R, Gaitonde SG, Woods SC, Seeley RJ. Fibroblast Growth Factor-19 Action in the Brain Reduces Food Intake and Body Weight and Improves Glucose Tolerance in Male Rats. Endocrinology (2013) 154(1):9-15. doi: 10.1210/en.2012-1891

58. Schaap FG. Role of Fibroblast Growth Factor 19 in the Control of Glucose Homeostasis. Curr Opin Clin Nutr Metab Care (2012) 15(4):386-91. doi: 10.1097/MCO.0b013e3283547171

59. Brufau G, Stellaard F, Prado K, Bloks VW, Jonkers E, Boverhof R, et al. Improved Glycemic Control With Colesevelam Treatment in Patients With Type 2 Diabetes Is Not Directly Associated With Changes in Bile Acid Metabolism. Hepatology (2010) 52(4):1455-64. doi: 10.1002/hep.23831

60. Tang MJ, Su JB, Xu TL, Wang XQ, Zhang DM, Wang XH. Serum Fibroblast Growth Factor 19 and Endogenous Islet Beta Cell Function in Type 2 Diabetic Patients. Diabetol Metab Syndr (2019) 11:79. doi: 10.1186/s13098-019-0475-1

61. Gerhard GS, Styer AM, Wood GC, Roesch SL, Petrick AT, Gabrielsen J, et al. A Role for Fibroblast Growth Factor 19 and Bile Acids in Diabetes Remission After Roux-En-Y Gastric Bypass. Diabetes Care (2013) 36(7):1859-64. doi: $10.2337 / \mathrm{dc} 12-2255$

62. Bhatnagar S, Damron HA, Hillgartner FB. Fibroblast Growth Factor-19, a Novel Factor That Inhibits Hepatic Fatty Acid Synthesis. J Biol Chem (2009) 284(15):10023-33. doi: 10.1074/jbc.M808818200

63. Miyata M, Sakaida Y, Matsuzawa H, Yoshinari K, Yamazoe Y. Fibroblast Growth Factor 19 Treatment Ameliorates Disruption of Hepatic Lipid Metabolism in Farnesoid X Receptor (Fxr)-Null Mice. Biol Pharm Bull (2011) 34(12):1885-9. doi: 10.1248/bpb.34.1885

64. Alisi A, Ceccarelli S, Panera N, Prono F, Petrini S, De Stefanis C, et al Association Between Serum Atypical Fibroblast Growth Factors 21 and 19 and Pediatric Nonalcoholic Fatty Liver Disease. PloS One (2013) 8(6):e67160. doi: 10.1371/journal.pone.0067160

65. Wojcik M, Janus D, Dolezal-Oltarzewska K, Kalicka-Kasperczyk A, Poplawska K, Drozdz D, et al. A Decrease in Fasting FGF19 Levels Is Associated With the Development of Non-Alcoholic Fatty Liver Disease in Obese Adolescents. J Pediatr Endocrinol Metab (2012) 25(11-12):1089-93. doi: 10.1515/jpem-2012-0253

66. Schreuder TC, Marsman HA, Lenicek M, van Werven JR, Nederveen AJ, Jansen PL, et al. The Hepatic Response to FGF19 Is Impaired in Patients With Nonalcoholic Fatty Liver Disease and Insulin Resistance. Am J Physiol Gastrointest Liver Physiol (2010) 298(3):G440-5. doi: 10.1152/ajpgi. 00322.2009

67. Younossi ZM, Ratziu V, Loomba R, Rinella M, Anstee QM, Goodman Z, et al. Obeticholic Acid for the Treatment of Non-Alcoholic Steatohepatitis: Interim Analysis From a Multicentre, Randomised, Placebo-Controlled Phase 3 Trial. Lancet (2019) 394(10215):2184-96. doi: 10.1016/S0140-6736(19)33041-7

68. Harrison SA, Rinella ME, Abdelmalek MF, Trotter JF, Paredes AH, Arnold HL, et al. NGM282 for Treatment of Non-Alcoholic Steatohepatitis: A Multicentre, Randomised, Double-Blind, Placebo-Controlled, Phase 2 Trial. Lancet (2018) 391(10126):1174-85. doi: 10.1016/S0140-6736(18)30474-4

69. Gallego-Escuredo JM, Gomez-Ambrosi J, Catalan V, Domingo P, Giralt M, Fruhbeck G, et al. Opposite Alterations in FGF21 and FGF19 Levels and Disturbed Expression of the Receptor Machinery for Endocrine Fgfs in Obese Patients. Int J Obes (Lond) (2015) 39(1):121-9. doi: 10.1038/ijo.2014.76

70. Gomez-Ambrosi J, Gallego-Escuredo JM, Catalan V, Rodriguez A, Domingo P, Moncada R, et al. FGF19 and FGF21 Serum Concentrations in Human Obesity and Type 2 Diabetes Behave Differently After Diet- or SurgicallyInduced Weight Loss. Clin Nutr (2017) 36(3):861-8. doi: 10.1016/ j.clnu.2016.04.027 
71. Mraz M, Lacinova Z, Kavalkova P, Haluzikova D, Trachta P, Drapalova J, et al. Serum Concentrations of Fibroblast Growth Factor 19 in Patients With Obesity and Type 2 Diabetes Mellitus: The Influence of Acute Hyperinsulinemia, Very-Low Calorie Diet and PPAR-Alpha Agonist Treatment. Physiol Res (2011) 60(4):627-36. doi: 10.33549/physiolres.932099

72. Tomlinson E, Fu L, John L, Hultgren B, Huang X, Renz M, et al. Transgenic Mice Expressing Human Fibroblast Growth Factor-19 Display Increased Metabolic Rate and Decreased Adiposity. Endocrinology (2002) 143 (5):1741-7. doi: 10.1210/endo.143.5.8850

73. Fu L, John LM, Adams SH, Yu XX, Tomlinson E, Renz M, et al. Fibroblast Growth Factor 19 Increases Metabolic Rate and Reverses Dietary and LeptinDeficient Diabetes. Endocrinology (2004) 145(6):2594-603. doi: 10.1210/ en.2003-1671

74. Ge H, Baribault H, Vonderfecht S, Lemon B, Weiszmann J, Gardner J, et al. Characterization of a FGF19 Variant With Altered Receptor Specificity Revealed a Central Role for FGFR1c in the Regulation of Glucose Metabolism. PloS One (2012) 7(3):e33603. doi: 10.1371/journal.pone.0033603

75. Nicholes K, Guillet S, Tomlinson E, Hillan K, Wright B, Frantz GD, et al. A Mouse Model of Hepatocellular Carcinoma: Ectopic Expression of Fibroblast Growth Factor 19 in Skeletal Muscle of Transgenic Mice. Am J Pathol (2002) 160(6):2295-307. doi: 10.1016/S0002-9440(10)61177-7

76. Desnoyers LR, Pai R, Ferrando RE, Hotzel K, Le T, Ross J, et al. Targeting FGF19 Inhibits Tumor Growth in Colon Cancer Xenograft and FGF19 Transgenic Hepatocellular Carcinoma Models. Oncogene (2008) 27(1):8597. doi: 10.1038/sj.onc. 1210623

77. French DM, Lin BC, Wang M, Adams C, Shek T, Hotzel K, et al. Targeting FGFR4 Inhibits Hepatocellular Carcinoma in Preclinical Mouse Models. PloS One (2012) 7(5):e36713. doi: 10.1371/journal.pone.0036713

78. Miura S, Mitsuhashi N, Shimizu H, Kimura F, Yoshidome H, Otsuka M, et al. Fibroblast Growth Factor 19 Expression Correlates With Tumor Progression and Poorer Prognosis of Hepatocellular Carcinoma. BMC Cancer (2012) 12:56. doi: 10.1186/1471-2407-12-56

79. Touat M, Ileana E, Postel-Vinay S, Andre F, Soria JC. Targeting FGFR Signaling in Cancer. Clin Cancer Res (2015) 21(12):2684-94. doi: 10.1158/ 1078-0432.CCR-14-2329

80. Zhou Q, Lui VW, Yeo W. Targeting the PI3K/Akt/Mtor Pathway in Hepatocellular Carcinoma. Future Oncol (2011) 7(10):1149-67. doi: $10.2217 /$ fon. 11.95

81. Goetz R, Mohammadi M. Exploring Mechanisms of FGF Signalling Through the Lens of Structural Biology. Nat Rev Mol Cell Biol (2013) 14(3):166-80. doi: $10.1038 / \mathrm{nrm} 3528$

82. Teng Y, Zhao H, Gao L, Zhang W, Shull AY, Shay C. FGF19 Protects Hepatocellular Carcinoma Cells Against Endoplasmic Reticulum Stress via Activation of FGFR4-GSK3beta-Nrf2 Signaling. Cancer Res (2017) 77 (22):6215-25. doi: 10.1158/0008-5472.CAN-17-2039

83. Zhao H, Lv F, Liang G, Huang X, Wu G, Zhang W, et al. FGF19 Promotes Epithelial-Mesenchymal Transition in Hepatocellular Carcinoma Cells by
Modulating the GSK3beta/Beta- Catenin Signaling Cascade via FGFR4 Activation. Oncotarget (2016) 7(12):13575-86. doi: 10.18632/oncotarget.6185

84. Repana D, Ross P. Targeting FGF19/FGFR4 Pathway: A Novel Therapeutic Strategy for Hepatocellular Carcinoma. Diseases (2015) 3(4):294-305. doi: 10.3390/diseases3040294

85. Mouzeyan A, Choi J, Allayee H, Wang X, Sinsheimer J, Phan J, et al. A Locus Conferring Resistance to Diet-Induced Hypercholesterolemia and Atherosclerosis on Mouse Chromosome 2. J Lipid Res (2000) 41(4):573-82. doi: 10.1016/S0022-2275(20)32405-6

86. Phan J, Pesaran T, Davis RC, Reue K. The Diet1 Locus Confers Protection Against Hypercholesterolemia Through Enhanced Bile Acid Metabolism. J Biol Chem (2002) 277(1):469-77. doi: 10.1074/jbc.M107107200

87. Vergnes L, Lee JM, Chin RG, Auwerx J, Reue K. Dietl Functions in the FGF15/19 Enterohepatic Signaling Axis to Modulate Bile Acid and Lipid Levels. Cell Metab (2013) 17(6):916-28. doi: 10.1016/j.cmet.2013.04.007

88. Lee JM, Ong JR, Vergnes L, de Aguiar Vallim TQ, Nolan J, Cantor RM, et al. Diet1, Bile Acid Diarrhea, and FGF15/19: Mouse Model and Human Genetic Variants. J Lipid Res (2018) 59(3):429-38. doi: 10.1194/jlr.M078279

89. Wang XK, Liao XW, Huang R, Huang JL, Chen ZJ, Zhou X, et al. Clinical Significance of Long Non-Coding RNA DUXAP8 and Its Protein Coding Genes in Hepatocellular Carcinoma. J Cancer (2020) 11(20):6140-56. doi: $10.7150 /$ jca. 47902

90. Graham PS, Kaidonis G, Abhary S, Gillies MC, Daniell M, Essex RW, et al. Genome-Wide Association Studies for Diabetic Macular Edema and Proliferative Diabetic Retinopathy. BMC Med Genet (2018) 19(1):71. doi: 10.1186/s12881-018-0587-8

91. Peng D, Wang J, Zhang R, Jiang F, Tang S, Chen M, et al. Common Variants in or Near ZNRF1, COLEC12, SCYL1BP1 and API5 Are Associated With Diabetic Retinopathy in Chinese Patients With Type 2 Diabetes. Diabetologia (2015) 58(6):1231-8. doi: 10.1007/s00125-015-3569-9

Conflict of Interest: The authors declare that the research was conducted in the absence of any commercial or financial relationships that could be construed as a potential conflict of interest.

Publisher's Note: All claims expressed in this article are solely those of the authors and do not necessarily represent those of their affiliated organizations, or those of the publisher, the editors and the reviewers. Any product that may be evaluated in this article, or claim that may be made by its manufacturer, is not guaranteed or endorsed by the publisher.

Copyright (c) 2022 Wang, Frey and Kohli. This is an open-access article distributed under the terms of the Creative Commons Attribution License (CC BY). The use, distribution or reproduction in other forums is permitted, provided the original author(s) and the copyright owner(s) are credited and that the original publication in this journal is cited, in accordance with accepted academic practice. No use distribution or reproduction is permitted which does not comply with these terms. 